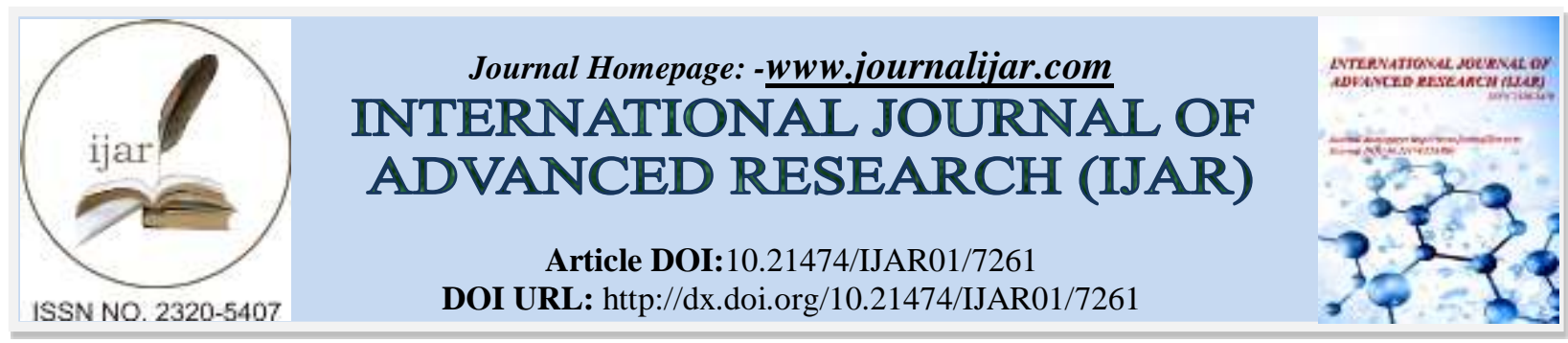

RESEARCH ARTICLE

\title{
ASSESSMENT OF LANGUAGE DELAY AMONG 0-3 YEAR CHILDREN ATTENDING THE WELL BABY CLINIC IN A TERTIARY CARE CENTRE USING LEST (0-3 YEARS).
}

\section{Dr. Rajeshwari $\mathbf{N}^{1}$ and Dr. Lavanya $\mathbf{R}^{2}$.}

1. DCH, MD (Paediatrics), PGDDN, Consultant and Head of the Department, Paediatrics, Developmental Neurologist, Head of Child Development Centre, Dr. Kamakshi Memorial Hospital, Pallikaranai, Chennai.

2. DCH, DNB (Paediatrics), Senior Registrar, Dr. Kamakshi Memorial Hospital, Pallikaranai, Chennai.

\section{Manuscript Info}

Manuscript History

Received: 11 April 2018

Final Accepted: 13 May 2018

Published: June 2018

Keywords:-

Language delay, LEST.

\section{Abstract}

The study is a cross sectional study of 200 children conducted using Language Evaluation Scale Trivandrum (LEST 0-3) in the age group birth to 3 years to assess the prevalence of language delay in children attending Well baby clinic in a tertiary care centre in Chennai.

The total percentage of children with one or more item delay by LEST was $19 \%$. $6.5 \%$ children had two item delay in the present study. $4.5 \%$ had three or more item delay.

Copy Right, IJAR, 2018,. All rights reserved.

\section{Introduction:-}

Language development is a process that starts early in human life and moves from simple to complex, assessment of the same should be a central part of every well-child visit.

The children who have communication problems may develop behaviour problems and difficulty to read and write later in life [1]. Children with language problems in preschool are at risk of poor educational achievement in school age and are at increased risk of developing emotional and behavioural disorders [2].

Hence early intervention is advocated to prevent or decrease the severity of language delay in school age and increase academic success in school. Intervention given or started during infancy or preschool age is shown to have a greater positive effect than services provided at school age [3].

Prevalence of 3.8\% [4] speech delay in Western studies and 4.5\% [5] in Indian literature indicate the need for screening all infants, toddlers and young children.

The need of the hour is a simple but reliable test that can be performed with minimum training, not requiring sophisticated equipment and less time consuming so as to be used in the community level in early intervention programs. In the West, many tools are available, for example Early Language Milestone Scale for 0-3 years (by James Coplan) and Receptive Expressive Emergent Language Scale (REELS). [6] But these are not generally accepted in community setting as they are time consuming and need technical expertise.

LEST (0-3years) was designed, developed and validated at the Child Development Centre, Government Medical College, Trivandrum. [7] [8] It is simple to understand as well as easy to be used by a health worker in the 
community to identify probable language delay among 0-3 year children, so as to enable mother to initiate speech and language stimulation at home itself with appropriate referral to a center for intervention when required.

Paediatricians are in an excellent position to identify children's speech and language problems early during the well baby and immunization visits and to make appropriate referrals for further evaluation and treatment services.

\section{Materials and Methods:-}

The study was conducted in the Well baby clinic, Department of Paediatrics, Dr. Kamakshi Memorial Hospital, Pallikaranai, Chennai. Informed consent was taken from parents. This is a cross sectional descriptive study of 200 children of age group birth to 3 years attending well baby clinic of a tertiary care centre, Dr. Kamakshi Memorial Hospital from April 2014 to June 2014.

Inclusion Criteria was children in the age group of 0-3 years attending the outpatient clinic of Paediatric Department for routine check-up and vaccination. Children with severe or chronic illness and delay in other domains of development like gross motor, fine motor and social-personal were excluded.

Study was done using a Proforma consisting of Socio-demographic parameters like age, sex, family order. Details of parental age, education, occupation and socio-economic status are assessed by modified Kuppuswamy scale [9]. Speech and Language assessment is done using Language Evaluation Scale, Trivandrum (0-3 years). [4][7]

Interpretation of language delay using LEST [4][7]:

\begin{tabular}{|l|l|}
\hline Normal - All items done & Suspect - Two items not done \\
\hline Questionable - One item not done & Delay - Three or more items not done \\
\hline
\end{tabular}

\section{Results:-}

\section{Age and Speech Delay:-}

Out of 200 children in age group of $0-3$ years in the present study ,30.5\% were in the age group of 0-6 months, $27.5 \%$ in the range of 7-12 months , $19 \%$ in the group 13-18 months , 14.5\% between 19-24 months and rest between 2-3 years.

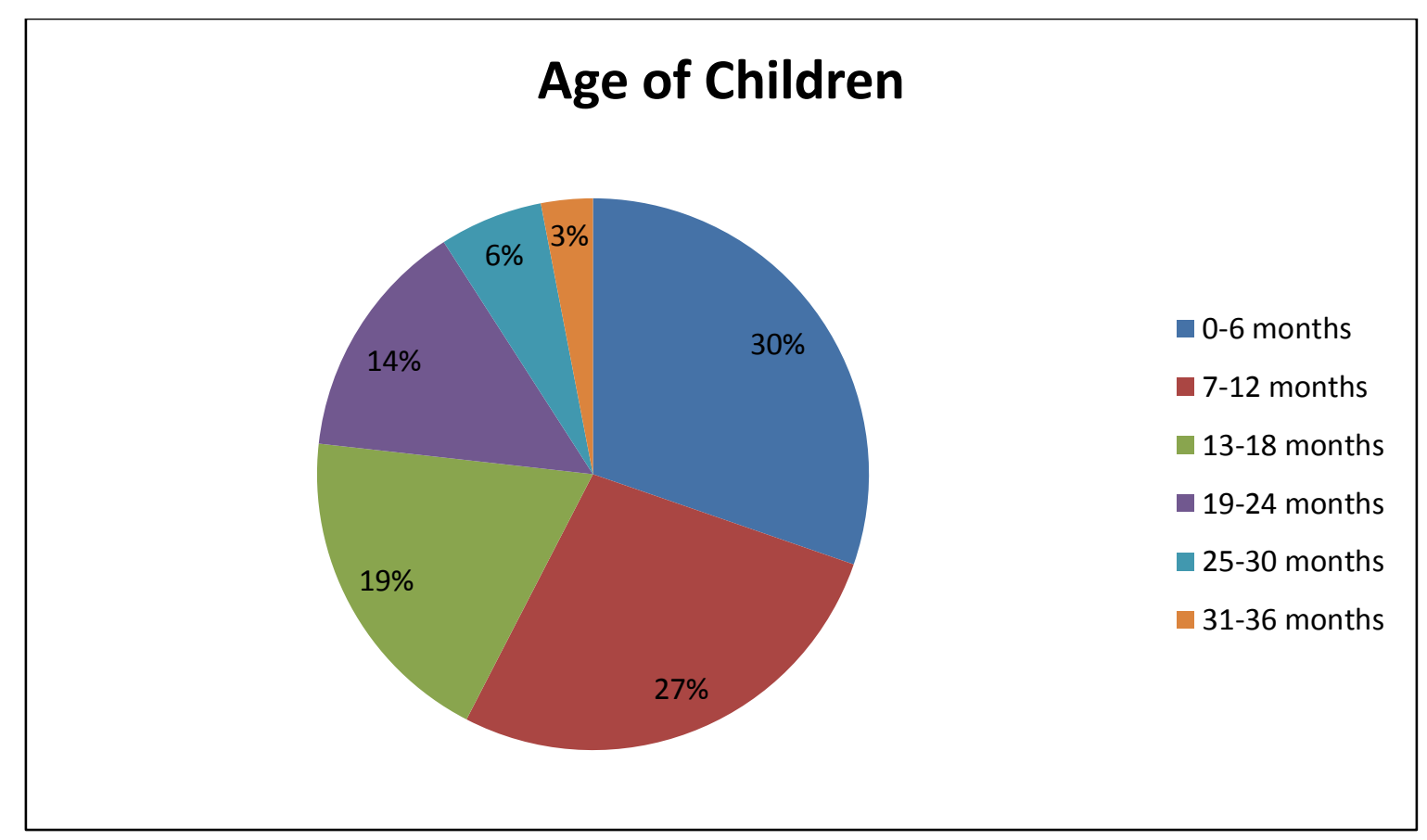

Figure 1:- AGE OF CHILDREN 
Present study was limited to age group of 0-3 years and children were sampled as random sample. No statistical significance was obtained between the age of the children and speech and language delay $(\mathrm{p}=0.244)$. However it was interesting to note that delay was predominantly found after the age of 1 year.

Table 1:-COMPARISON OF AGE AND LEST INTERPRETATION

\begin{tabular}{|c|c|c|c|c|c|c|c|}
\hline \multirow{2}{*}{$\begin{array}{l}\text { Lest } \\
\text { Interpretation8 }\end{array}$} & \multicolumn{6}{|c|}{ Age of children (in months) } & \multirow[b]{2}{*}{ Total } \\
\hline & $0-6$ & $7-12$ & 13-18 & $19-24$ & 25-30 & 31-36 & \\
\hline Normal & $52(85.2 \%)$ & $45(81.8 \%)$ & $28(73.7 \%)$ & $22(75.9 \%)$ & $11(91.7 \%)$ & $4(80.0 \%)$ & $162(81.0 \%)$ \\
\hline Questionable & $8(13.1 \%)$ & $8(14.5 \%)$ & $5(13.2 \%)$ & $4(13.8 \%)$ & - & - & $25(12.5 \%)$ \\
\hline Suspect & $(1.6 \%)$ & $2(3.6 \%)$ & $1 \quad(2.6 \%)$ & - & - & - & $(2.0 \%)$ \\
\hline Delay & - & - & $4 \quad(10.5 \%)$ & $3 \quad(10.3 \%)$ & $1 \quad(8.3 \%)$ & $1(20.0 \%)$ & $(4.5 \%)$ \\
\hline Total & $61(100 \%)$ & $55(100 \%)$ & $39(100 \%)$ & $29(100 \%)$ & $12(100 \%)$ & $5(100 \%)$ & $200(100 \%)$ \\
\hline
\end{tabular}

Gender and Speech Delay:-

In the present study, there were 95 male children (47.5\%) and $105(52.5 \%)$ were female children. No significant statistical difference was observed for speech and language delay among both sexes $(\mathrm{p}=0.252)$.

Table 2:-COMPARISON OF GENDER AND LEST INTERPRETATION

\begin{tabular}{|l|l|l|l|}
\hline \multirow{2}{*}{ Lest Interpretation } & \multicolumn{2}{|c|}{ Gender } & \multirow{2}{*}{ Total } \\
\cline { 2 - 3 } & Male & Female & \\
\hline Normal & $73(76.8 \%)$ & $89(84.8 \%)$ & $162(81.0 \%)$ \\
\hline Questionable (1 item delay) & $15(15.8 \%)$ & $10(9.5 \%)$ & $25(12.5 \%)$ \\
\hline Suspect (2 item delay) & $1(1.1 \%)$ & $3(2.9 \%)$ & $4(2.0 \%)$ \\
\hline Delay (3 or more item delay) & $6(6.3 \%)$ & $3(2.9 \%)$ & $9(4.5 \%)$ \\
\hline Total & $95(100.0 \%)$ & $105(100.0 \%)$ & $200(100 \%)$ \\
\hline
\end{tabular}

Lest Interpretation:-

In the present study out of 200 children, 162 children( $81 \%)$ were found to be normal.38 children(19\%) were found to have one or more item delay by LEST assessment. Among the 38 children, 25 children(12.5\%) had one item delay, 4 children( $2 \%)$ had two item delay and 9 children(4.5\%) had three item delay.6.5\% children had two or more item delay.

Table 3:-LEST INTERPRETATION

\begin{tabular}{|l|l|l|}
\hline Lest Interpretation & Number & Percentage \\
\hline Normal & 162 & 81.0 \\
\hline Questionable & 25 & 12.5 \\
\hline Suspect & 4 & 2.0 \\
\hline Delay & 9 & 4.5 \\
\hline Total & 200 & 100.0 \\
\hline
\end{tabular}




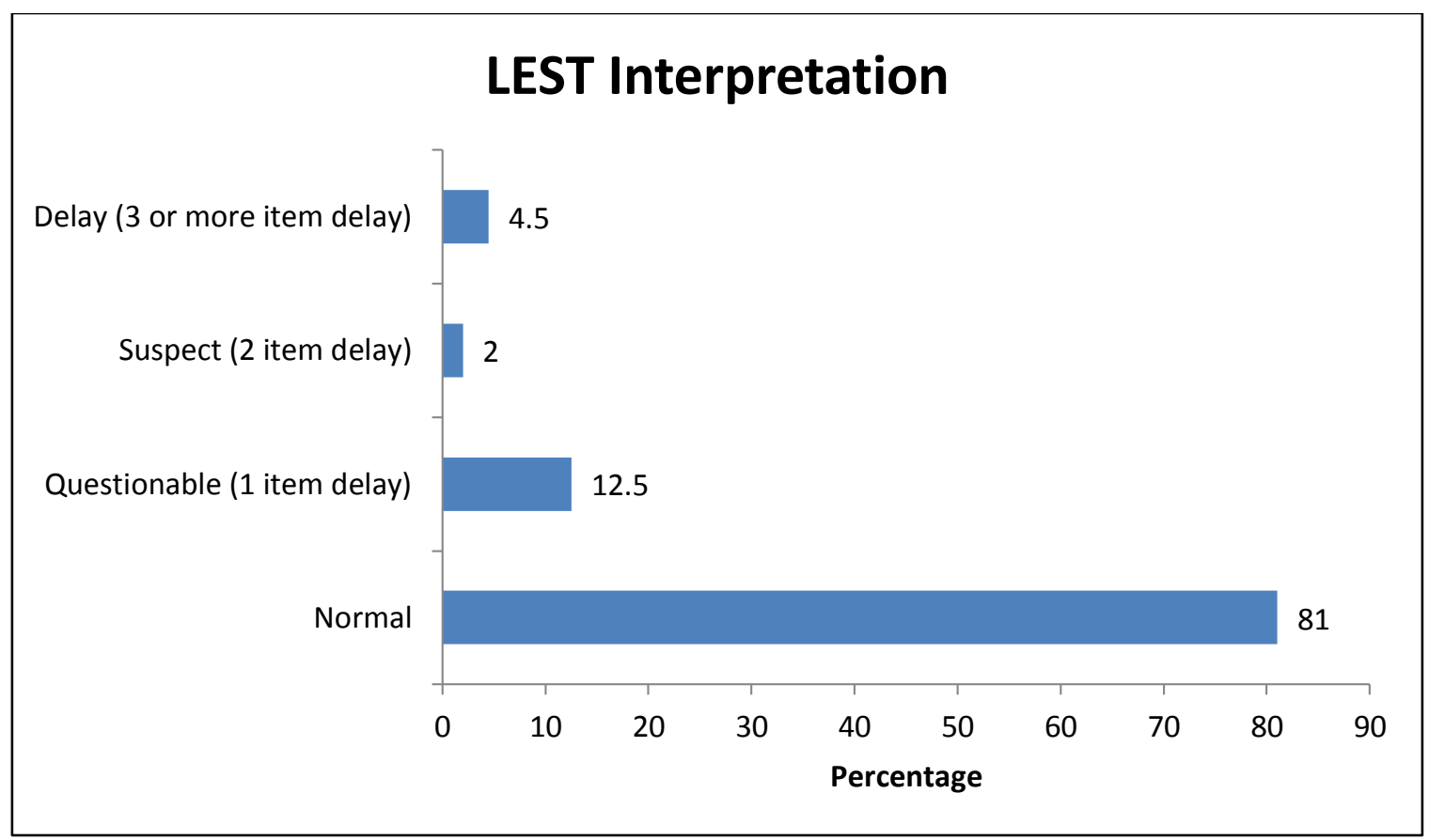

Figure 2:- LEST INTERPRETATION

\section{Discussion and Conclusion:-}

A cross sectional study in 200 children was conducted using Language Evaluation Scale Trivandrum (LEST 0-3) from the age group birth to 3 years of age to find out the prevalence of language and speech delay.

In the present study out of 200 children, 162 children (81\%) were found to be normal. 38 children (19\%) were found to have one or more item delay by LEST assessment. Among the 38 children, 25 children (12.5\%) had questionable delay (one item delay), 4 children (2\%) had suspect delay (two item delay) and 9 children (4.5\%) had delay (three item delay).

In a study conducted by CDC Trivandrum, there was $4.5 \%$ language delay. In a Cochrane study [10] there was approximately $6 \%$ language delay. In the study by Shiji et al [11], prevalence of speech delay was 5.5\% .In comparison our study showed a prevalence of speech delay was $4.5 \%$ which is comparable. All the above studies show a prevalence of about 4-6\% language delay.[7]

Table 4:- PREVALENCE OF SPEECH AND LANGUAGE DELAY IN VARIOUS STUDIES

\begin{tabular}{|l|l|}
\hline Studies & Prevalence \\
\hline OUR study & $\mathbf{4 . 5 \%}$ \\
\hline CDC TVM & $4.5 \%$ \\
\hline Cochrane [10] & $6 \%$ \\
\hline Shiji et al [11] & $5.5 \%$ \\
\hline
\end{tabular}

According to a recent Cochrane study, for pre-school children 2-4.5 years, the prevalence rates for combined speech and language delay ranges from 5\% -8\% and of language delay alone from 2.3\%-19\%. Prevalence of speech and language delay in children without any neonatal risk factors was observed to be $4.5 \%$.

\section{Recommendations:-}

It has been shown that language disorders top the list of childhood disability in children less than 3 years of age. Delay in the language development is an early marker of Pervasive Developmental disorders, Intellectual disabilities and Specific Learning disorders.

1. The prevalence of $4.5 \%$ language delay in children aged 0-3 years attending well baby clinic emphasises the need for early screening programs. 
2. Speech and language assessment is a must during the routine evaluation of young children in paediatric clinics.

3. LEST is a simple, culturally appropriate, locally relevant, validated screening tool which can be used to identify early speech delay

4. Early recognition of speech and language delay enables early intervention practices.

\section{References:-}

1. Backer 1, Cantwell D. A prospective psychiatric follow up of children with speech/language disorder. Journal of the American Academy of child and Adolescent psychiatry. 1987; 26:546-53.

2. Prizant B. Communication disorders and emotional / behavioural disorders in children. Journal of Speech and Hearing Disorders. 1990; 55:179-92.

3. Barnett W, Escobar C. Economic costs and benefits of early intervention, Hand book of early childhood Intervention,3rd Edn, In SJ Meisels \& JP Shoukoff:1990; 560-825.

4. Nair MKC, George B, Philip E. Trivandrum Developmental Screening Chart. Indian Pediatr.1991; 28:869-72.

5. Frankenburg WK, Dobbs JB. The Denver Developmental Screening Test. J Pediat. 1967; 71:181-91.

6. Bzoch KR, League R. Receptive-expressive Emergent Language Scale. 1st edition. Gainseville: The Tree of Life Press; 1971.

7. Kavitha SR, Nair MKC. Validation of LEST (1-2 years) against REELS Language Evaluation Scale Trivandrum (1-2 Research Form 2006) Against Receptive Expressive Emergent Language Scale. Teens .2006; 1(2):29-31

8. MKC Nair, GS Harikumaran Nair, AO Mini, S Indulekha, S Letha and PS Russel. Development and Validation of Language Evaluation Scale Trivandrum for Children Aged 0-3 years - lest (0-3). Indian Pediatr. 2013; 50:463-67

9. Sushama Bai S. History taking. Clinical Evaluation of Newborns, Infants and Children $2^{\text {nd }}$ Edition. Jaypee Brothers Medical Publishers. 2009; Chapter 3:13

10. Heidi D. Nelson, Peggy Nygren, Miranda Walker, Rita Panoscha. Screening for Speech and Language Delay in Preschool Children: Systematic Evidence Review for the US Preventive Services Task Force. Paediatrics.2007; 117:e298-e319.

11. Shiji K. Jacob. "Speech and Language Assessment using LEST 0-6 among children aged 0 to 6 years". Journal of Evolution of Medical and Dental Sciences 2013; Vol. 2, Issue 52, December 30; Page: 10083-10088. 